\title{
A Case Study on the Establishment of a National Quality Infrastructure in Korea
}

\author{
Heekyeom Yoo ${ }^{1, *}$ \\ ${ }^{1}$ Korea Research Institute of Standards and Science, Office of Policy Research, Daejeon, Republic of \\ Korea
}

\begin{abstract}
Standards are involved in the series of actions of individuals and groups such as governments and markets with different interests and purposes. Standards are created through social and scientific coordination and are used at the national and international level. This study examines the standard governance of Korea, which is structured and implemented around three important elements of national quality infrastructure: standardization, conformity assessment, and metrology, from the legal and organizational perspectives. Article 127 (2) of the Constitution of the Republic of Korea states "the State shall establish a system of national standards" and the Framework Act on National Standards and the Enforcement Decree enacted in 1999 for the establishment and implementation of national quality infrastructure. As three pillars of national quality infrastructure, standardization, conformity assessment, and metrology are interrelated and indispensable for each other to provide a consistent and reliable social as well as scientific and technical grounds for development and implementation of national standards. Drawing on the Korean case of national standards in respect to earthquake risk management, this study examines the problems of imbalance and disconnection of these quality management elements. In conclusion, future plans for national quality assurance are suggested from the perspective of a network governance.
\end{abstract}

\section{Introduction}

Since the past, the importance of unified weights and measures has been universally appreciated, and it goes without question that the maintenance of weights and measures is recognized as a core responsibility of any nation. Following the Korean War in the 1950s, Korea laid the economic and social foundations to rebuild the nation, starting with the FiveYear Economic Development Plans that were first established in the 1960s. As a result, Korea accomplished unprecedented economic growth and rose up to become a top 10 nation in trade in the 1980s. With the globalization of international trade and the growing need to secure standards on advanced technology, Korea emphasized the importance of

\footnotetext{
* Corresponding author: hky@kriss.re.kr
} 
standards during this crucial period by stating "the State shall establish a system of national standards" as an economic-related Article in the Constitution. The Framework Act on National Standards was enacted and enforced to stipulate detailed provisions for the establishment of a national standards system, or a national quality infrastructure.

Three important elements for the establishment and operation of a national quality infrastructure are standardization, metrology, and conformity assessment. Metrology provides the scientific and technical basis for standardization and conformity assessment. Standardization involves the documentation of the quality requirements of products and systems, including technical regulations. Conformity assessment is the activities of confirming the technical requirements through tests and inspections based on the two aforementioned elements. The Framework Act on National Standards of Korea states that systems are to be established and implemented for each of the three elements.

Standards are created through modes of social and scientific coordination when individuals or groups such as governments and markets with different interests participate in a series of activities related to standards. Standards can be redefined from the perspective of governance, which is a mode of social as well as scientific and technical coordination that is used to solve national, social, and public issues. Governance can be categorized into three types: hierarchical, market, and network.

This study aims to redefine national standards activities from the different perspectives of governance through analyzing a Korean case of earthquake risk management. First, the legal and organizational system of the Korean national quality infrastructure is introduced in the perspective of standardization, conformity assessment, and metrology. Next, the study explores the case of legal and implementing system of NQI in the field of earthquake and discusses the problems of malfunction of national standards system with policy suggestions for activation of harmonized and effective NQI.

\section{Standards, Governance and National Quality Infrastructure}

\subsection{Standards and Governance}

Social coordination is the act of individuals or organizations with different interests working together to overcome various national social issues [1]. Governance is broadly defined as a collective term for modes of social coordination that are used by governments as methods to solve social and public issues of the nation [2-3]. Standards are defined as the results of individual standardization efforts that have been approved by an accredited body; standards are enacted through agreements, approved by a recognized institution, and are defined as documents that provide rules, guidelines, or properties for common and repeated use for the purpose of establishing an optimal level of order within a given range [4]. Therefore, the proposal, agreement, approval, and implementation of standards is a series of processes involving a series of actions related to standards pursued by individuals with various interests or organizations with differing interests (such as governments and markets) to come to agreements through social coordination. Standards derived from such agreements are utilized in both national and international capacities [5]. In this sense, it is meaningful from the perspective of governance as a mode of social coordination to reinterpret standards that involve various interest groups to form agreements; this study will refer to this as 'standard governance'. 
There have been several studies on governance as a mode of social coordination. Most notably, Jessop proposed ex-post coordination through exchange, ex-ante coordination through imperative top-down planning, and coordination based on reflexive selforganization as types of social coordination. [6]. In addition, Beetham proposed the market, hierarchy, and democracy, whereas Jeffery proposed price, authority, and trust as various types of social coordination modes [1,7]. In addition to these studies, there have been various studies on the types of social coordination, which can be categorized into three types: hierarchical, market, and networks [8].

Hierarchical governance is a traditional bureaucracy paradigm in which social coordination is forced through overall planning, intentional design, or top-down planning for the purpose of solving social issues by an individual or body that has been formally endowed with power by a known official political authority or regulation. Market governance is a form of social coordination that is achieved through voluntary exchanges and competition between actors with varying interests without the presence of a political authority characterized by coercion. Lastly, network governance is a form of social coordination that solves social issues through the voluntary participation of actors with equal status that are political authorities that do not rely on legal force. The actors actively participate in the process of determining the rules to define their interactions and voluntarily participate in activities that are necessary for implementing concluded matters.

Standard governance can also be categorized into the three aforementioned hierarchical, market, and network categories and be developed through three stages according to the circumstances of each nation. This study analyzes the Korean case of standard governance by focusing on the three key elements of the national quality infrastructure: standardization, metrology, and conformity assessment.

\subsection{National Quality Infrastructure (NQI)}

The International Organization for Standardization (ISO), the World Bank, and overseas national metrology institutes in countries such as the U.S. and Germany define standardization, metrology, and conformity assessment as the key elements of a national quality infrastructure [9-13]. In Korea, the Framework Act on National Standards, which is the highest-level law on standards, states that a national standards system, which refers to a national quality infrastructure, is to be established. Standardization is defined as "the activity of establishing, with regard to actual or potential problems, provisions for common and repeated use, aimed at the achievement of the optimum degree of order in a given context" [4]. In addition, it can be defined as the organized activity of defining reasonable standards for objects, concepts, methods, and procedures and creating rules and guidelines for the utilization of the standards. Document standards and technical regulations are the most notable results of standardization. Metrology can be defined as the science of measurement and its application, and the representative results of metrology are measurement standards [14]. Conformity assessment is defined as "demonstration that specified requirements relating to a product, process, system, person or body are fulfilled", and include activities such as testing, inspection, and verification [15].

The three elements of the national quality infrastructure are interdependent. Metrology provides a scientific and technological basis for standardization and conformity assessment. Technical requirements of products and systems are standardized through documentation as document standards in the process of standardization. Based on the two aforementioned 
elements, conformity assessment is conducted to confirm the technical requirements through tests and inspections. In the field of standardization, national standards are established and utilized in accordance with international standards established by international standards institutions such as ISO and the International Electrotechnical Commission(IEC). In the metrology field, measurement standards established by national metrology institutes of each nation are mutually recognized and disseminated in accordance with international procedures to ensure that metrological traceability is maintained across the entire industry. In the field of conformity assessment, evaluations are conducted on whether national standards or international standards are met. In other words, a nation's national quality infrastructure is established, advanced, and developed as the nation collaborates with international organizations in the fields of standardization, metrology, and conformity assessment to conform to international standards. As a result, such efforts guarantee the quality of products and processes of the nation in international trade, and mutual recognition reduces redundant waste and enables active exchange.

\section{Standard Governance of Korea}

\subsection{Standard Governance from a Legal Perspective}

In 1961, Korea released the first of its Five-Year Economic Development Plans of 19621966 with the establishment the Industrial Standardization Act and the Weights and Measures Act as part of the national standardization strategy. These act describes a standard specification system for domestic industrial products to improve and ensure the quality of mining and manufacturing products as well as to reduce costs and improve price competitiveness by simplifying/specializing systems and standardizing the terms and specifications of goods. In 1963, Korea joined ISO/IEC to establish a framework for the adaptation of domestic standards in accordance with international standards, and national standards were disseminated/expanded through the implementation of the KS mark certification system.

As a result of implementing series of the national economic development plans, Korea succeeded in establishing itself as an advanced industrial nation by achieving 10 billion dollars in exports in 1977. In particular, with the fourth Five-Year Plan (1977-1981), the Korean government focused on transitioning from a labor-intensive industry to a technology-based industry as its primary goal. To this, the government established a national calibration system to improve the quality and performance of domestically produced industrial products and has continually strived to strengthen legal bases to encourage the utilization of the system, since there is still little awareness on standards and conformity assessment for quality assurance in the domestic level.

Internationally, in order to remove technical barriers in international trade between nations under the WTO system, the Korean government signed the TBT agreement in 1980, which made it mandatory to comply with international standards when establishing standards that affect trade (such as technical regulations) and when conducting conformity assessments through tests and inspections. Accordingly, the Korea government added the article "the State shall establish a system of national standards" to Chapter 9 of the Constitution, Economic Provisions Article 128(2), which provides a framework at the national level for establishing a national standards system. Subsequently, the Industrial Standardization Act was amended in 1983 to internationalize the Korean Industrial Standards (KS) in accordance with the global trend to promote international trade and technology transfer. In 
1987, a long-term five-year industrial standardization plan was established to promote the standardization of technology-based industries and new technology industries such as information and biology. In particular, the participation of private organizations was promoted. Such standardization policies highlight the continual efforts of the government for the specialization and segmentation of domestic standards in addition to the conformity of domestic standards to international standards through plans such as the five-year plan for the advancement of industrial standards (1993-1997) and the five-year plan for international standardization (2004-2008).

The Weights and Measures Act, which was enacted/enforced in 1961, can be traced back to the when Korea signed the Metre Convention in 1959. The Metre Convention is an international agreement for the purpose of enacting and disseminating the metric system. The Weights and Measures Act was enacted to develop the national economy by disseminating the metric system, now referred to as the International System of Units (SI), throughout the country as soon as possible to establish measurement standards and to conduct proper measurements. In 1993, with advancements in the industry and the rapid development of technology, the precision measurement system of the industry was supplemented to improve the precision and accuracy of measurements regarding products and raw materials. In addition, the aforementioned act was amended to secure precision measurement systems in the industrial and science and technology fields through efforts such as the development of high-precision, high-value-added products by ensuring the quality competitiveness of products.

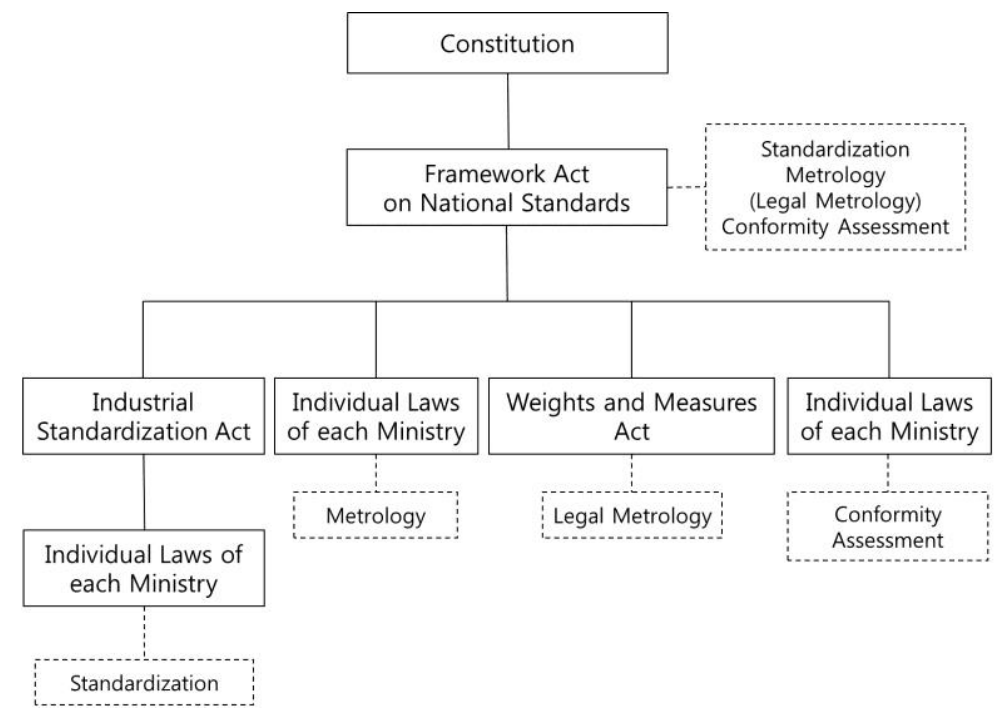

Fig. 1. Standard governance from a legal system perspective

The actual legal and institutional basis for the establishment of the national standards system stipulated by the Constitution of the Republic of Korea can be traced to 1999 when the Framework Act on National Standards was enacted and enforced. From an international standpoint, this is the period when the measurement community, under the administration of the International Committee on Weights and Measures (CIPM), signed a CIPM-MRA between national metrology institutes for the removal of technical barriers in international trade. The Framework Act on National Standards is comprised of articles for the 
establishment of systems for standardization, metrology, and conformity assessment, the three elements of the national quality infrastructure referred to in Chapter 2 Article 2 [16]. Chapter 1, Article 1 of the Framework Act on National Standards stipulates that the purpose of this act is to contribute to facilitating the innovation of science and technology, upgrading the industrial structure, and developing the information society, thereby enhancing national competitiveness and improving the welfare of citizens by providing for fundamental matters for the establishment of the national standards system. In addition, the act stipulates that it shall govern economic and social activities in all areas, to which national standards based on science and technology shall apply mutatis mutandis. The Framework Act on National Standards is comprised of five chapters titled General Provisions, Establishment of National Standard Policies, Establishment of National Standards System, Operation and Management of National Standards System, and Supplementary Provisions, as shown in $\langle$ Table 1>, and embodied in 34 clauses.

Table 1. Composition of the Framework Act on National Standards

\begin{tabular}{|c|c|}
\hline Composition & Key Content \\
\hline - Chapter I General Provisions & $\begin{array}{l}\text { - Purpose, Scope of Application, Definitions, } \\
\text { Responsibilities and Duties of State, etc. }\end{array}$ \\
\hline $\begin{array}{l}\text { - Chapter II Establishment of National } \\
\text { Standard Policies }\end{array}$ & $\begin{array}{l}\text { - Deliberative Committee on National Standards, } \\
\text { Formulation of Master Plans for National Standards, } \\
\text { Formulation of Implementation Plans for National } \\
\text { Standards etc. }\end{array}$ \\
\hline $\begin{array}{l}\text { - Chapter III Establishment of National } \\
\text { Standard System }\end{array}$ & $\begin{array}{l}\text { - Classification of Units of Measurement, Base Units, } \\
\text { Derived Units, Measurement Units Outside } \\
\text { International System of Units, Representative Institute } \\
\text { of National Measurement Standards, Establishment of } \\
\text { National Calibration System, Legal Weight and Measure, } \\
\text { Enactment and Diffusion of Document Standards etc. }\end{array}$ \\
\hline $\begin{array}{l}\text { - Chapter IV Operation and Management } \\
\text { of National Standards System }\end{array}$ & $\begin{array}{l}\text { - Overall Control of National Standards System, } \\
\text { Establishment of Conformity Assessment System, } \\
\text { Introduction of Examination System for Certification of } \\
\text { Standard, Introduction of Integrated National } \\
\text { Certification Mark, Accreditation, etc. of Laboratories, } \\
\text { Mutual Recognition of Conformity Assessment, Pursuit } \\
\text { of Policies Related to Technical Barriers to Trade etc. }\end{array}$ \\
\hline - Chapter IV-2 Deleted & - Deleted \\
\hline - Chapter V Supplementary Provisions & - Delegation of Entrustment of Authority \\
\hline
\end{tabular}

The Definitions Article of Chapter 1 defines basic concepts related to standards. A total of 21 terms are defined, including standards concepts such as national standards, international standards, measurement standards, national measurement standards, and codified standards, and terms such as International System of Units, legal weights and measures, calibration, traceability, accreditation of a laboratory, and conformity assessment. In the second chapter on the Establishment of National Standard Policies stipulates matters regarding the establishment and operation of a Deliberative Committee on National Standards and the formulation and implementation of master plans and implementation plans for national 
standards. The Deliberative Committee on National Standards is under the jurisdiction of the Minister of Trade, Industry and Energy and is composed of up to 25 members of public officials in the rank of vice ministers from related central administrative agencies, including the chairperson. The Committee serves the role of deliberating on key matters for the effective coordination between ministries related to national standards and master plans for national standards. The government is required to formulate master plans for national standards every five years, and the Minister of Trade, Industry and Energy is required to consolidate plans from each related central administrative agency to establish master plans and have them finalized following deliberation by the Deliberation Committee. In addition, the heads of related central administrative agencies are required to formulate and implement implementation plans for national standards each year according to the master plan. The third chapter on the Establishment of National Standards System specifies systems that lay the foundations for the establishment of national standards systems by stipulating matters related to measurement units, base units, derived units, the International System of Units, the establishment of systems related to measurement standards that specify the role of the representative institute of national measurement standards, the establishment of national calibration systems, the certification and diffusion of reference materials, the enactment and diffusion of reference standards, legal weight and measure, the enactment and diffusion of industrial standards, and the pursuit of projects for the establishment of national measurement standards. The fourth chapter on the Operation and Management of National Standards System stipulates various matters on the operation of a standards system, such as the overall control of the national standards system, the establishment of conformity assessment systems, product certification, the introduction of examination systems for the certification of standards, the introduction of an integrated national certification mark, the accreditation of laboratories, and the certification of quality management systems and environmental management systems. In addition, the chapter stipulates matters on the operation and management of the national standards system for the consistency of national standards and compliance with international standards, such as the mutual recognition of conformity assessment, mutual recognition of the results of testing for certification, enhancement of cooperation on international standards, and the pursuit of policies related to technical barriers of trade.

As such, the Framework Act on National Standards stipulates details for the establishment of systems for standardization, metrology, and conformity assessment, the three elements of the national quality infrastructure. In particular, Chapter 3, Article 17 of the Framework Act on National Standards on Legal Weight and Measure states that relevant matters shall be governed by the provisions of the Weights and Measures Act, and Chapter 3, Article 18 of the same act on the Enactment and Diffusion of Document Standards states that relevant matters shall be governed by the provisions of acts related to the standardization of products, such as the Industrial Standardization Act and the Framework Act on Broadcasting Communications Development. In addition, through individual laws that individual ministries enact/enforce, each ministry and sector runs individual systems based on the Framework Act on National Standards in a manner that is suitable for the respective ministry or sector to standardize document standards and technical regulations, conduct projects to maintain the measurement traceability of measurement equipment managed by the relevant ministries, and operate testing/inspection organizations and a conformity assessment system. For example, certain ministries enact/enforce acts for the fields of metrology and conformity assessment, such as the Environmental Testing and Inspection Act of the Ministry of Environment and the Act on Testing and Inspection in the Food and Drug Industry of the Ministry of Food and Drug Safety. In the aforementioned acts, it is 
stated that the level of management should comply with international standards through projects for the improvement of the precision and accuracy of testing and inspection technology to ensure the capabilities of testing and inspection organizations, projects for ensuring traceability according to the Framework Act on National Standards, projects to improve the reliability of organizations that conduct tests/inspections, and others.

\subsection{Standard Governance from an Organizational System Perspective}

Since the enactment of the Framework Act on National Standards in 1999, Korea has established and operated systems for the three elements of a national quality infrastructure (standardization, metrology, and conformity assessment) as Framework Acts. The Korea Agency for Technology and Standards (KATS) under the Ministry of Trade, Industry and Energy is the main institute responsible for matters related to standards and the national standards body (NSB). KATS is responsible for policies, systems, and regulations related to national and international measurement standards such as measurement standards, reference standards, document standards, and technical regulations. In the metrology field, the Korea Research Institute of Standards and Science (KRISS), which is a government-funded science and technology research institute under the Ministry of Science and ICT and the representative national metrology institute (NMI) stipulated in Article 13 of the Framework Act on National Standards, is responsible for the implementation of basic units, establishment and dissemination of national measurement standards, research and development of measurement standards and measurement science and technology, and international comparison of measurement standards. In the conformity assessment field, the Korea Laboratory Accreditation Scheme (KOLAS) of KATS, which is the National Accreditation Body (NAB) recognized by the International Laboratory Accreditation Cooperation (ILAC), is responsible for the operation of accreditation systems for institutions for calibration, testing, inspection, proficiency testing, medical testing, and reference material production. In addition, KOLAS is responsible for collaborations and exchange with national and international organizations related to standardization. Accreditation matters such as the accreditation and post-management of product certification institutions are conducted through the Korea Accreditation System (KAS). Therefore, we can see that Korea, similar to the aforementioned international organizations and overseas national metrology institutes, operates a national standards system based on the three elements of standardization, metrology, and conformity assessment, as shown in Figure 2 . 


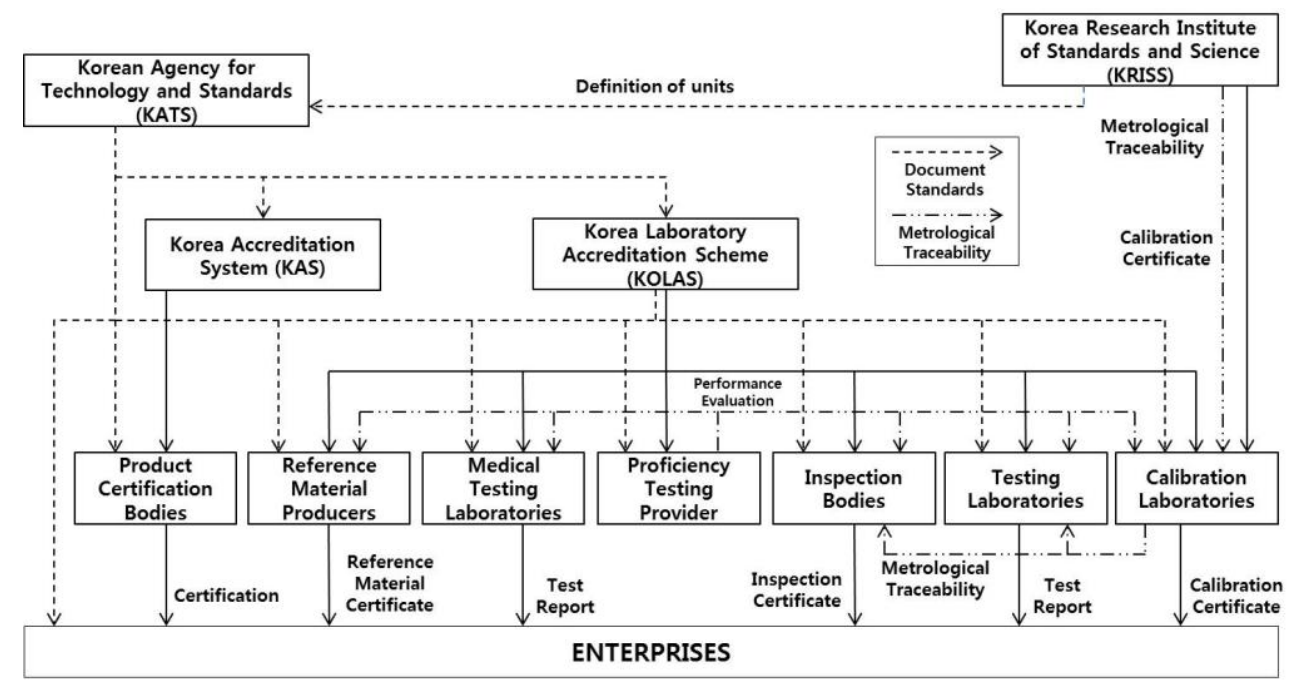

Fig. 2. Standard governance from an organizational system perspective

In particular, KRISS, which is responsible for establishing and disseminating national measurement standards of Korea in the metrology field, was established in 1975 during the final years of the Third Five-Year Economic Development Plan (1972-1976). As Korea's exports reached 5 billion dollars during this period, the quality assurance of export goods became a key national task, and standards became a necessity for quality control. In addition, as the industrial structure shifted from a light industry to a heavier industry, there was greater demand for standards on measurement with high precision accuracy. In order to support international trade, measurement units should match the International System of Units. However, although the Weights and Measures Act defined measurement units, a national standards system could not be established due to the lack of connection between national standards and calibration tasks. As such, the government decided to establish a national metrology institute with autonomy and founded KRISS. In 1980, all governmentfunded science and technology research institutes in the different branches were transferred to the Ministry of Science and ICT to create the current governance format. Afterwards, when the Framework Act on National Standards was enacted in 1999, Article 13 on the Representative Institute of National Measurement Standards was created and KRISS was designated as this institute, cementing the status of KRISS as the institute that establishes and disseminates national measurement standards of Korea.

When observing governance from the national quality infrastructure perspective, although it may seem that legislations related to standardization, metrology, and conformity assessment that are embodied in the constitution, the Framework Act on National Standards, and the individual laws of each branch are established in a systematic manner from a legal system perspective, operations are conducted differently according to the circumstances of each branch, as the Framework Act on National Standards delegates authority to each department. Although sectors such as environment, food, health care, and national defense specify the need to meet international standards in terms of standardization, metrology, and conformity assessment, certain sectors operate according to the circumstances of the ministry or the domestic scene instead of conforming with international standards. In terms of organization, of the three elements of the national quality infrastructure, standardization and conformity assessment are operated by the government through KATS, which is under 
the Ministry of Trade, Industry and Energy. The metrology field is operated by KRISS, which is a public institution and government-funded research institute that is sensitive to government policies as it is controlled by the government in terms of manpower and budget. Whereas KATS and KOLAS, which are responsible for standardization and conformity assessment, are part of the Ministry of Trade, Industry and Energy, KRISS is a public institution under the Ministry of Science and ICT; as such, two branches are involved.

From the perspective of standard governance, Korea still retains a hierarchical governance structure led by the government. Although attempts are being made to change this structure to a market governance structure to increase market participation, in reality, the current governance is closer to a hierarchical governance structure. For example, in the standardization field, KATS has operated a National Standard Coordinator System since 2011, and in 2017, KATS selected private experts from the five technology fields of smart manufacturing, smart health, smart home appliances, autonomous cars, and services to establish/pursue national and international standardization strategies and standardization roadmaps. In addition, KATS discovered/planned core technology standardization projects to connect such projects with standardization projects. Since 2008, the Cooperation Organization for Standards Development (COSD) system has been in operation. This system designates private standardization institutions that are experts and representatives of designated fields of standards development as collaborating institutions to swiftly respond to the standardization demands of the industry and reflect the opinions of stakeholders in national standards. As of 2017, 65 institutions have been designated and are active. In the field of standardization, continuous efforts are being made to effectively develop/manage national standards and to enhance private standardization capacity, and it can be seen as a transition from being government-led to a private-centered field [17].

However, although the Framework Act on National Standards states that the Deliberative Committee on National Standards, which establishes master plans for the establishment, maintenance, and development of the national standards system and oversees the overall coordination of national standards policies, shall be operated with the inclusion private experts, a total of 13 public officials in the rank of Vice Minister from 13 government branches, including The Office for Government Policy Coordination, the Ministry of Science and ICT, the Ministry of the Interior and Safety, the Ministry of Agriculture, Food and Rural Affairs, and the Ministry of Health and Welfare are included as committee members, whereas only three private members. In addition, for acts that are operated as laws of individual ministries, the government places greater emphasis on standardization and conformity assessment instead of building a balanced national quality infrastructure for standardization, conformity assessment, and metrology. In most cases, operations are government-led, and there is a need for changes in the role of the government to foster active private participation.

\section{Case Study of the Korean Earthquake Field}

\subsection{The Surrounding Environment of Korea}

Korea is geographically located in an area that is affected by the Pacific Ring of Fire along with Japan and China. As a result, Korea has continually suffered damages caused by natural earthquakes. There have been several earthquakes that became significant issues around the world. In 2011, the 9.0-magnitude 2011 Tohoku earthquake in Japan caused a powerful tsunami that resulted in many casualties in addition to the leakage of radioactive 
materials at the Fukushima Nuclear Power Plant. This earthquake remains a significant issue in Japan to this day. In 2008, an 8.0-magnitude earthquake hit Sichuan and resulted in tens of thousands of casualties. From the political, economic, and social perspectives, it is imperative to be able to monitor artificial earthquakes caused by North Korean nuclear tests at all times. Since North Korea's first nuclear test in 2006, there have been a total of six artificial earthquakes as of 2017. This is a highly sensitive issue not only within the Korean Peninsula but also worldwide, which emphasizes the importance of observation and response measures for earthquakes. In addition, as a nation that operates 24 domestic nuclear power plants, Korea monitors the potential of nuclear-related disasters and the safety of nuclear power plants through the observation of earthquakes. Therefore, it is clear that the monitoring of earthquakes has substantial importance in the Korean Peninsula from multiple viewpoints.

In November, 2017, a 5.4-magnitude earthquake occurred at Pohang, North Gyeongsang Province, which was the second largest earthquake that was observed in Korea (behind the 5.8-magnitude earthquake that hit Gyeongju on September, 2016) since implementing earthquake monitoring in 1978. The Gyeongju earthquake caused significant human and property damage and was followed by a 4.5 -magnitude earthquake a week after the main tremor. Public fear was heightened by the aftershocks, of which there were over 400 occurrences. The recent Pohang earthquake was a major earthquake that occurred a year after the Gyeongju earthquake, and caused damages that were five times greater than the Gyeongju incident. With the frequent occurrence of large-magnitude earthquakes, the public perception shifted and it became widely recognized that the Korean Peninsula was no longer a safe zone, resulting in greater public awareness on matters related to earthquakes. Moreover, despite a request for improvement by The Board of Audit and Inspection of Korea in 2008 that states that calibrations should be conducted for seismic observation equipment management, it was discovered in a 2016 National Assembly inspection that no improvement measures were taken for eight years. With the occurrence of large earthquakes and damages caused to the Korean people, earthquakes became a significant national and social issue and focal point. Due to the series of events that caused the nation recognize the importance of earthquake observation, Korea amended laws on earthquakes in 2017 and began to enact/enforce Framework Acts at the national level on the observation and warning of earthquakes/tsunamis/volcanos.

Seismic observation equipment in Korea is installed, operated, and managed according to the separate laws of the Ministry of the Interior and Safety and the Korea Meteorological Administration (KMA). The Ministry of the Interior and Safety specifies the standards for the type and specifications of installations in major facilities that are susceptible to damage from earthquakes, and is tasked with measuring seismic acceleration. KMA monitors earthquakes using seismic observation equipment installed at 206 observatories (as of 2017) that monitor earthquake, tsunami, and volcanic activity. KMA cooperates with organizations that operate seismic observation equipment to monitor earthquakes. Such organizations include those designated by the laws of Ministry of the Interior and Safety, including the Korea Institute of Geoscience and Mineral Resources (KIGAM), the Korea Institute of Nuclear Safety (KINS), and organizations under the Korea Electric Power Corporation (KEPCO), such as Korea Hydro \& Nuclear Power Co, Ltd. (KHNP). In addition, KMA works with ministries such as the Ministry of Science and ICT and the Ministry of the Interior and Safety to monitor earthquakes in Korea and operate national safety response, alerts, and countermeasures. 


\subsection{State of Seismic Observation Equipment Management in Korea}

Seismic observation equipment in Korea is installed, operated, and managed for two purposes under two laws. The first is for the measurement of seismic acceleration managed under the Act on the Preparation for Earthquakes and Volcanic Eruptions of the Ministry of the Interior and Safety, in which seismic observation equipment are installed in facilities designated by the act. The other purpose is for seismic measurement equipment managed under the Act on the Observation and Warning of Earthquakes, Tsunamis and Volcanic Eruptions of the Korea Meteorological Administration, in which seismic observation equipment are installed and operated in 206 observatories nationwide.

The purpose of the Act on the Preparation for Earthquakes and Volcanic Eruptions, which was enacted by the Ministry of the Interior and Safety in 2009, is to prescribe matters necessary for the observation of, prevention of, provision against, and action against earthquake, tsunami, and volcanic activity, earthquake-proof measures, and research and technical development to reduce earthquake and volcanic disasters in order to protect the lives and property of the people and major infrastructure from disasters due to earthquakes, tsunamis, and volcanic activity at the national and local government levels [18]. The same law stipulates that KMA shall formulate and promote a comprehensive plan for an earthquake, tsunami, and volcanic activity observation network. Agencies that participate as observation agencies include KMA, KIGAM, KINS, agencies that engage in research related to electric power under KEPCO, agencies that engage in investigations and research related to the sea under the Ministry of Oceans and Fisheries, the Korea Gas Corporation (KOGAS), the Korea Rural Community Corporation (KRC), the Korea Water Resources Corporation (K-water), and the Korea Institute of Ocean Science \& Technology (KIOST). In addition, when installing observation equipment, observation agencies are required to submit an observation plan that includes the purpose for observation, reasons for installation, the location of installation, performance and specifications, methods of acquiring, transmitting, and storing observation data, and a plan for the utilization of the observation results. The same act also stipulates in detail the standards for installation.

A person who builds or manages major facilities that are apprehended to be damaged by earthquakes are required to measure seismic acceleration for the facility in question. Such facilities include central administrative agencies and the government offices of local governments, national universities, public buildings that are either $200 \mathrm{~m}$ or 50 floors in height, airport facilities, dams and reservoirs, suspension and cable-stayed bridges, highpressure gas storage facilities, high-speed railways, hydroelectric power facilities and thermal power facilities. The same law stipulates that seismic acceleration measuring instruments shall be managed to function normally at all times, and that the Ministry of the Interior and Safety shall regularly conduct document inspections and site inspections regarding the implementation status each year, and prescribe and implement detailed standards for the measurement of seismic acceleration and management thereof.

The Act on the Observation and Warning of Earthquakes, Tsunamis, and Volcanic Eruptions of KMA was enacted in 2014 with the purpose of prescribing matters necessary for the observation and warning of earthquakes, tsunamis, and volcanic eruptions to protect the lives and property of the people from earthquakes, tsunamis, and volcanic eruptions [19]. This law is composed of 30 Articles across seven Chapters: Chapter I General Provisions, Chapter II Observation of Earthquakes, Tsunamis, and Volcanic Eruptions, Chapter III Warning of Earthquakes, Tsunamis, and Volcanic Eruptions, Chapter IV Management of Data on Earthquakes, Tsunamis, and Volcanic Eruptions, Chapter V 
Technical Development and Domestic and International Cooperation, Chapter VI Supplementary Provisions, and Chapter VII Penalty Provisions. The law stipulates that, starting from 2017, a master plan for the observation and warning of earthquakes, tsunamis, and volcanic eruptions shall be formulated and implemented every five years. The master plan must include matters such as the present situation of and prospect for earthquakes, tsunamis, and volcanic eruptions in Korea or overseas, the establishment and operation of an earthquake early-warning system, and the development of technologies for the observation and analysis of earthquakes, tsunamis, and volcanic eruptions. Presently, the 2017 first master plan for the observation and warning of earthquakes, tsunamis, and volcanic eruptions (2017 2021) has been formulated and is in the process of implementation [20].

The second chapter of this law stipulates in detail matters on the methods of observing earthquakes, tsunamis, and volcanic eruptions, the establishment and operation of observatories and observation networks, support for observatories, the protection of observation facilities, the locations for installing observations, and the inspection of observation devices. In particular, in terms of the inspection of observation devices (which will be discussed from the perspective of the national quality infrastructure), the act stipulates that observation devices should be inspected regularly, and matters necessary for the time, method, etc. of inspecting observation devices shall be prescribed by Ordinance of the Ministry of Environment. Observation agencies are required to inspect observation devices every five years; however, equipment related to seismic acceleration measurement that are installed in major facilities specified in the Act on the Preparation for Earthquakes and Volcanic Eruptions of the Ministry of the Interior and Safety are excluded. In addition, there is an article stipulating that the following devices are waived from inspection for five years from the date the device was calibrated or the date the device passed a conformity assessment: measurement devices that have been calibrated by representative institute of national measurement standards and agencies responsible for national calibration tasks (as specified in the Framework Act on National Standards), measurement devices that have passed conformity assessments from agencies that have been approved by a certified organization, measurement devices that have passed conformity assessments from agencies designated by the Ministry of the Interior and Safety or KMA, measurement devices that have passed conformity assessments of or have been calibrated by certified overseas inspection or calibration agencies. In addition, the act stipulates the detailed inspection standards for each type of seismic observation equipment: velocity type seismometer, acceleration type seismometer, devices for the collection and processing of seismic observation data.

\subsection{Problems from the National Quality Infrastructure Perspective}

As mentioned in the previous section, the Act on the Observation and Warning of Earthquakes, Tsunamis, and Volcanic Eruptions stipulates that designated observatories are required to conduct inspections for seismic observation equipment every five years. Whereas it may seem as that seismic observation equipment are installed, operated, and managed effectively within the legal system, upon closer inspection of each of the key elements of the national quality infrastructure (standardization, metrology, and conformity assessment), we can find problems with the national quality infrastructure for earthquakes.

First, from the perspective of standardization, there are no details on specific performance inspection methods or procedures for the inspection of seismic observation equipment. 
Therefore, it is impossible to verify whether the testing and inspection institutions all used different methods or not. Second, there are no standards regarding the number of equipment that require performance inspections. Third, there are no specific details on regular inspections. Lastly, there is a substantial lack of specificity in terms of detailed documents standards for performance inspections and the regular maintenance and inspection of seismic measurement equipment. For example, there are no documents that specify the durability standards for seismic observation equipment.

From the metrology perspective, measurement traceability has yet to be achieved for existing seismic observation equipment that has already been installed and are in operation. As mentioned above in the standardization perspective, the lack of specific details such as the method, quantity, and durability for performance inspections of seismic observation equipment also results in a lack of methods of ensuring measurement traceability. In addition, as national measurement standards have yet to be established for the specific frequency range of the field of vibration measurement, the calibration of seismographs remains a challenge. Unlike conventional vibration sensors and measuring instruments, seismographs are required to measure minute vibrations with frequencies less than $0.01 \mathrm{~Hz}$. However, measurement standards have only been established for low frequencies of $0.1 \mathrm{~Hz}$; hence, frequency ranges of $0.01 \mathrm{~Hz}$ and lower are impossible to trace using national measurement standards. Therefore, despite legally being required to conduct inspections every five years, it is currently impossible to conduct inspections for certain ranges as national measurement standards have yet to be established for such ranges.

From the perspective of conformity assessment, there are no specific details regarding the institutions that conduct inspections of seismic observation equipment that are legally required every five years. It is not clear whether KMA should conduct the tasks itself, or whether it should designate professional institutions. In addition, there are no details such as the eligibility of such inspection institutions. Another issue the lack of professional institutions that are capable of inspecting seismic observation equipment. Earthquakerelated sensors that are installed in Korea are imported from overseas. In addition, there are no institutions that are capable of conducting inspections for all of the individual performance aspects of devices in the category of seismic observation equipment.

\subsection{Future Plans for Improvement}

This paper observed the problems of the national quality infrastructure of Korea for the earthquake field from the perspectives of standardization, metrology, and conformity assessment. It may seem like the national quality infrastructure for the earthquake field is systematically established and operated with it being specified in the acts of the legal system as well as being established and implemented in national Framework Acts. However, upon closer examination through the aforementioned three perspectives, various problems are revealed, all of which are closely related to one another.

In terms of standardization, most of the seismic observation equipment used in Korea are dependent on imports. As national standards were developed based on the performance and specifications of imported seismic observation equipment, the standards lack specific details and do not take into consideration traceability through national measurement standards and whether or not inspections were possible through professional institutions. In order to establish standards that are suitable for the domestic scene, standards should be considered from the metrology and conformity assessment perspectives. 
In terms of metrology, a significant amount of time and large investments are required to establish national measurement standards for a specific field and to provide services such as calibration and testing. Measurement standard research requires the continuous investment of manpower and funding for R\&D activities. In order for a country to have the international equivalence of its national measurement standards certified, international key comparisons (KC) should be performed and Calibration and Measurement Capabilities (CMC) should be registered at the website of the International Bureau of Weights and Measures (BIPM). However, this process is time-consuming and expensive. In addition, as various prerequisites should be met once national measurement standards are established to be able to provide the measurement standards as services to the public, systematic preparations should be made in advance.

In terms of conformity assessment, there is a need for the development of professional institutions and manpower for the inspection of seismic observation equipment. The fact that most seismic observation equipment in Korea depends on imports is evidence that Korea lacks the R\&D capabilities and potential for marketability in the field of earthquakes. Multiple facilities, substantial manpower, and significant time investment is required to inspect all performance aspects of seismic observation equipment; as such, it is imperative to review and realize the necessary inspection categories as well as the importance of each category. In addition, even if national measurement standards are established, professional institutions and manpower for the purpose of providing the standards as services cannot be developed in the short-term. For this reason, specific plans must be established in stages, and at the same time, relevant markets should be developed. All in all, systematic government support will be vital for long-term goals.

Fortunately, KMA is aware of the current situation and has established the first master plan concerning the Observation and Warning of Earthquakes, Tsunamis, and Volcanic Eruptions (2017 2021). In addition, KMA is in the process of establishing and implementing a comprehensive plan to solve the problems regarding the three elements, as previously described in Section 4.3. However, from the perspective of standard governance, there are limitations as these are attempts at constructing a national quality infrastructure through government-led hierarchical governance. Whereas KMA is responsible for the management of seismic observation equipment, and hence also relevant document standards, in terms of metrology, KRISS, a government-funded research institute under the Ministry of Science and ICT, is responsible for the establishment and dissemination of national measurement standards. In terms of conformity assessment, inspections of seismic observation equipment should be conducted by institutions that have been approved by the Korea Laboratory Accreditation Scheme (KOLAS) or markets that are capable of conducting inspections. It is imperative that the various stakeholders that participate in the fields of standardization, metrology, and conformity assessment understand the current situation and cooperate to complete the national quality infrastructure for the earthquake field. In addition, the government should strive to provide various stakeholders with the opportunity to actively cooperate to solve the heavily intertwined issues. This is due to the fact that various ministries, public institutions, and private groups need to follow systematic long-term plans to conduct $R \& D$ related to earthquakes, establish and disseminate national measurement standards, promote the domestic production of seismic observation equipment, and develop professional inspection institutions and personnel. 


\section{Conclusion}

This paper introduces the standard governance of Korea and examines the current state and problems of the national quality infrastructure in the field of earthquake. Following the Korean War, Korea's economic development was led by the government, and governmentled policies also drove the development of standards. However, there are increasing demands for new standards for quality assurance in various areas such as food, environment, and health care for safety and quality of life. In addition, the technical convergence of different disciplines and the emergence of new technologies such as artificial intelligence require a more collective and collaborative mode of governance that can link various stakeholders, policy makers, and academic professionals.

In this vein, the traditional government-led standards development has limitations in coordinating various social demands in terms of expertise and timeliness. Therefore, the government, rather than leading standards development, should establish efficient and reliable national standard system for various stakeholders and experts to actively participate in standards development. In addition, the government should strive for network governance by cooperating with other actors as equals in a horizontal, cooperative relationship.

In recent years, the biology field has risen as uncharted territory in terms of the development of national measurement standards. In addition, public demand and international needs regarding this field are increasing. In the case of the U.S., which is the most notable nation that uses a private-based decentralized standardization system, the U.S. Food and Drug Administration (FDA, a government policymaker), the National Institutes of Health (NIH, a national medical research institute), the National Institute of Standards and Technology (NIST, a national metrology institute), and Thermo Fisher Scientific (a company that produces and sells reference materials) formed a consortium to promote the development of national measurement standards in the early stages of a development plan for national measurement standards in the biology field, which involves reference materials for the molecular diagnosis of cancer. Each actor joined the consortium with the goal of using the developed standards in mind. Of the three types of governance, this is an example of network governance, as the development of national measurement standards is not led by the government, but rather involved stakeholders actively participate in a mode of social coordination to solve social issues through cooperation. In addition, from the perspective of national quality infrastructure, the principal actors of standardization, metrology, and conformity assessment are actively participating in the consortium.

This study suggests a redefinition of national standards in the viewpoint of a network governance which is a mode of social as well as scientific and technical coordination for quality assurance in the subject fields through a harmonized role of standardization, conformity assessment, and metrology. Although the scope of this study was limited to the case study of the earthquake field in Korea, this study is significant as it examined standards from the perspective of governance and analyzed a case study of a specific field according to the three elements of the national quality infrastructure to propose improvements. Additionally, this study proposes a solution for the analysis of national quality infrastructure problems in other fields, which involves organically connecting the aforementioned three elements to establish a national quality infrastructure. 


\section{References}

1. Beetham D., Bureaucracy, $2^{\text {nd }}$ edition, Buckingham: Open University Press (1996)

2. Rhodes R., Understanding Governance: Policy Networks, Governance, Reflexivity and Accountability. Bristol, PA: Open University Press (1997)

3. Pierre, J., Debating Governance, Oxford University Press (2000)

4. ISO/IEC GUIDE 2:2004, Standardization and related activities - General vocabulary (2004)

5. Timmermans S, Epstein S, A World of Standards but not a Standards World: Toward a Sociology of Standards and Standardization, Annu. Rev. Sociol., 36:69-89 (2010)

6. Jessop B, The Governance of Complexity and the Complexity of Governance: Preliminary Remarks on the some Problems and Limits of Economic Guidance, Beyond Market and Hierarchy: Interactive Governance and Social Complexity, 95 (1997)

7. Jeffrey L, Bradach and Robert G. Eccles, Price, Authority and Trust: From Ideal Types to Plural Forms, Annu. Rev. Sociol. 15(1), 97-118 (1989)

8. Walter W. Powell, Neither Market nor Hierarchy: Network Forms of Organization, The Sociology of Organizations: Classic, Contemporary, and Critical Readings, 315 (2003)

9. ISO/UNIDO, Building Trust; The Conformity Assessment Toolbox (2009)

10. Tippmann, C and J.-L. Racine, The National Quality Infrastructure, World Bank (2013)

11. Guasch, J. L., J.-L. Racine, I. Sanchez, and M. Diop, Quality Systems and Standards for a Competitive Edge, World Bank (2007)

12. PTB, A National Quality Infrastructure (2007)

13. NIST, An Assessment of the United States Measurement System (2007)

14. ISO/IEC GUIDE 99:2007, International vocabulary of metrology - Basic and general concepts and associated terms (VIM) (2007)

15. ISO/IEC 17000:2004, International Standard - Conformity assessment - Vocabulary and general principles (2004)

16. Framework Act on National Standards (Enforcement Date 13. Jun, 2018, Act No.15176), National Law Information Center, Ministry of Government Legislation,

http://www.law.go.kr/engLsSc.do?tabMenuId=tab45\&query=\%EA\%B5\%AD $\%$ EA\%B0 $\% 80 \%$ ED\%91\%9C\%EC\%A4\%80\%ЕA\%B8\%B0\%ЕB\%B3\%B8\%ЕB\%B2\%95\#

17. Korean Agency for Technology and Standards, National Technology and Standards White Paper (2017) 
18. Act on the Preparation for Earthquakes and Volcanic Eruptions (Enforcement Date 27. Jun, 2018, Act No.15297), National Law Information Center, Ministry of Government Legislation,

http://www.law.go.kr/engLsSc.do?tabMenuId=tab45\&query=\%EC\%A7\%80\%EC\%A7 $\% 84 \% \mathrm{ED} \% 99 \% 94 \% \mathrm{EC} \% 82 \% \mathrm{~B} 0 \% \mathrm{EC} \% 9 \mathrm{E} \% \mathrm{AC} \% \mathrm{ED} \% 95 \% \mathrm{~B} 4 \% \mathrm{~EB} \% 8 \mathrm{C} \% 80 \% \mathrm{EC} \%$ B1\%85\%EB\%B2\%95\#

19. Act on the Observation and Warning of Earthquakes, Tsunamis and Volcanic Eruptions (Enforcement Date 26. Jul, 2017, Act No.14839), National Law Information Center, Ministry of Government Legislation,

http://www.law.go.kr/engLsSc.do?tabMenuId=tab45\&query=\%EC\%A7\%80\%EC\%A $7 \% 84 \%$ EC $\%$ A7\% $80 \%$ EC\%A7\%84\%ED\%95\%B4\%EC\%9D\%BC\#

20. Korea Meteorological Administration, Master plan for the observation and warning of earthquakes, tsunamis, and volcanic eruptions (2017 2021) (2017) 